The polarographic curves in the cancer reactions must be an additive expression of the substances mentioned plus something not yet elucidated. The substance must be rather stable if we may take the polarographic curve as a criterion; it can stand boiling for hours in open vessels; it cannot be extracted from acid, neutral, or alkaline urine by shaking with chloroform, benzene, petrol, carbon tetrachloride, trichlorethylene, or olive oil. By fractional addition of methanol, ethanol, or acetone, the substance seems to be adsorbed to the precipitates in proportion to their amounts. It can be adsorbed (though not quantitatively) on fuller's earth at $p \mathrm{H}$ $4 \cdot 6$ and regained by elution at $p H \quad 7$ by pyridine.

The substance in serum does not pass a 'Cellophane' membrane ; the substance in urine passes a 'Cellophane' membrane, but very slowly.

Bile (from necropsies) gives very low curves and cerebrospinal fluid (from patients) gives almost 'empty' curves.

In a recent paper, Waldschmidt-Leitz ${ }^{4}$ puts forward the view that the 'cancer substance' in serum may be a sulphur-free mucoid; we can confirm his experiments with fractional precipitation with ethanol, but our experiments with urine scarcely support the mucoid hypothesis, as normal urine does not contain mucoids and mucoids do not pass 'Cellophane' membranes.

We wish to thank Dr. Fritz Lipmann, of the Biological Institute, Carlsberg Foundation, who kindly sent us some of the synthetic compounds.

Frants Bergh.

O. M. Henrtques.

Finsen Laboratory,

Finsen Institute and Radiumstation,

Ferrosan Research Laboratory,

C. G. Wot,FfBrandt. Copenhagen. June 27.

Bergh, Henriques, Schousboe, Nature, 141, 751 (1938). 2 Brdicka, Acta internat. Verein. Krebsbekämpfung, 3, 13 (1938).

' Brown, Lewis, Proc. Soc. Exp. Biol., Med., 36, 487 (1937).

- Waldschmidt-Leitz, Angewandte Chem., 51, 324 (1938).

\section{Two Active Proteins from Rattlesnake Venom}

WE have found the dry venom of the Brazilian rattlesnake (Crotalus $t$. terrificus) to contain about 60 per cent of a neurotoxic substance and about 10 per cent of a blood coagulating principle. The latter shows all the proteolytic as well as all the coagulating activity of the crude venom. It was not possible to obtain this protein in a homogeneous state or to crystallize it, but we were able to achieve in the best case a tenfold increase of activity. Since the blood coagulating and the proteolytic activity was always found in the same fraction, even when prepared in different ways, we believe that these two activities are due to the same protein. It can be obtained by saturating the venom solution to 40 per cent with ammonium sulphate, whereby it is precipitated adsorbed on inactive globulins. When removing the ammonium sulphate by dialysis, these globulins separate out and the supernatant solution contains the coagulating substance. It can be obtained as a colourless material on evaporating the water in the high vacuum after freezing. We were able further to purify the coagulating principle by redissolving it in distilled water and centrifuging off the undissolved material. Once it is highly purified, it shows the properties of an albumin. It can also be isolated from the mother liquors of the preparation of the neurotoxic principle.

This neurotoxic substance we could obtain pure and in the crystalline state, as will be described elsewhere in detail ${ }^{1}$. It is the first proteinic toxin which has so far been crystallized. It contains the whole neurotoxic and the whole hæmolytic activity of the venom. These two properties of many snake venoms have hitherto been attributed to two different substances, one an enzyme, the other a toxin. This substance we called crotoxin (Crotalus t. terrificus toxin). Crotoxin can be isolated from the fresh venom secretion by heat coagulation, precipitation at the isoelectric point and ammonium sulphate frac. tionation. Crotoxin crystallizes from pyridine acetate solution in thin quadratic plates which aggregate in very characteristic manner (see accompanying illustration). Repeated recrystallization does not alter the physiological properties or the analytical data.

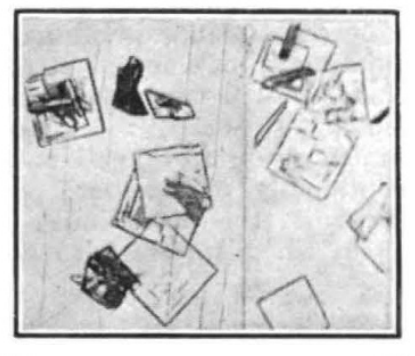

Crystalline crotoxin. $\times 96$.

The analysis shows crotoxin to contain $4 \cdot 0$ per cent of sulphur, which is more than in the crude venom. It has been previously shown ${ }^{2}$ that the sulphur in all venoms investigated here is bound at least partly in the form of $-S-S$-bonds, and that an opening of these linkages by reduction with cysteine $(-\mathrm{SH})$ inactivates the venoms just as is the case with insulin.

We have therefore determined the quantitative distribution of the sulphur in crotoxin, and found the following facts ${ }^{3}$ : the eystine content of $13 \cdot 2$ per cent corresponds to $87 \cdot 4$ per cent, the methionine content of $1 \cdot 36$ per cent to $7 \cdot 3$ per cent of the total sulphur. The cystine value is the mean of eight determinations using the Folin, Sullivan and Baern. stein methods. All agreed within $0 \cdot 3$ per cent. From the methionine value, which is the mean of three determinations agreeing within 0.05 per cent, a minimum molecular weight of 11,000 can be calcu. lated. The molecular proportion of methionine to cystine is exactly $1: 6$. One is tempted to believe that the actual molecular weight will be three or six times 11,000. A molecule of the weight 33,000 would contain eighteen cystines, three methionines and possibly two more sulphur. containing units which, however, cannot be disulphides, thiols, homologues of methionine or thiolactones.

K. H. Slotta.

H. Fraenkel-Conrat.

Department of Chemistry,

Instituto Butantan, São Paulo.

May 7.

${ }^{1}$ Slotta, K. H., and Fraenkel-Conrat, H., Ber. dtsch. Chem. Ges. (1938).

${ }^{2}$ Slotta, K. H., and Fraenkel-Conrat, H., Ber. dtsch. Chem. Ges., 71,264 (1938).

${ }^{3}$ Slotta, K. H., and Forster, W., Ber. dtsch. Chem. Ges. (1938). 